\title{
TO-INFINITIVE CLAUSES IN ACADEMIC DISCOURSE - NATIVE AND NON-NATIVE WRITERS COMPARED
}

\author{
Zuzana Kozáčiková
}

\begin{abstract}
The objective of the paper is to examine the use of non-finite clauses, more specifically to-infinitive clauses, in written academic discourse and the application of their syntactic and semantic properties in a selected corpus. Based on Quirk et al.'s (1985) subdivision they can be viewed as formal means of text formation and may have nominal, relative and adverbial meaning. This functional classification resembles to some extent that of subclausal units such as noun phrases and adverbs. The analysis focuses on subordinate to-infinitive clauses in selected papers found in Topics in Linguistics, an international scientific journal published by the Department of English and American Studies, Faculty of Arts, Constantine the Philosopher University in Nitra, Slovakia. Moreover, it tries to investigate possible differences in the application of the presented structure by native and non-native writers of English.
\end{abstract}

\section{Key words}

non-finite to-infinitive clauses, nominal to-infinitive clauses, stance, research papers, native writers, non-native writers

\section{Introduction}

Professional research writing has been conceptualized as a formal type of academic writing, the grammatical features of which are different from those of other types of discourse. Apart from some other grammatical devices, grammatical compression in academic discourse may be expressed with the use of non-finite to-infinitive clauses, which are the main focus of this paper. As far as terminology is concerned, to-infinitive clauses are viewed as subtypes of non-finite subordinate clauses. For Quirk et al. (1985: 1062) these are valuable sources of compression possessing nominal, adverbial and relative functions. In their nominal function they often indicate that the proposition they express is viewed as a possibility or a proposal rather than something already fulfilled. Similarly, Huddleston and Pullum (2005: 212-222) deal with a wide range of functions and uses of to-infinitivals with the extra reference to interrogative infinitives and simple versus complex catenative constructions. Alexander (1988: 303) comments on some common uses of to-infinitive clauses such as those of purpose with in order to and so as to (1), the latter event in a sequence - an event 
which is unexpected or sometimes unwelcome (2) and finally the to-infinitive (with verbs like hope, intend, mean and would like to) referring to the future or to an imaginary past (3).

(1) She was sent to England so as to be educated.

(2) She left home, never to be seen again.

(3) I would have liked to see it.

The concept of the to-infinitive across registers has been intensively discussed by Biber et al. (2002: 328) who go further in their classification, since apart from the main syntactic functions of infinitives as subject, extraposed subject, subject predicative, direct object, object predicative, adverbial, noun complement, noun postmodifier and part of an adjective phrase, they refer to their semantics - "infinitive clauses are more common in the written registers than in conversations. They report speech and mental states, and they are also used to report intentions, desires, efforts, perceptions, and other general actions" (ibid.). To sum up the above mentioned preview, to-infinitive clauses have been discussed by different authors in their grammar books (e.g. Quirk et al. 1985, Burton-Roberts 1997, Huddleston \& Pullum 2005, Leech \& Svartvik 1994) in connection with some other types of non-finite dependent clauses such as bare infinitives, -ing clauses and -ed participle clauses. More on their semantic aspects can be found predominantly in Biber et al. (2002), Biber (2006) and Biber and Gray (2010) who describe the range of grammatical features of academic prose in comparison to fiction, newspaper writing and conversation. Based on the findings, these clauses are actually one of the major linguistic devices used for giving directives. Their specific forms vary across subgenres of academic discourse. Moreover, the authors comment on the expression of stance in university register through different grammatical markers and view toinfinitives as one of them. In my view, an infinitival clause can be considered as an economical and transparent grammatical construction with various syntactic and semantic functions. Since academic discourse is characterized by an explicit organization and a high level of informativeness, I believe to-infinitive clauses are used for informative, descriptive and interpretive purposes.

\section{Material and methods}

The present paper deals with infinitival clauses, more specifically to-infinitives in academic prose, particularly in research articles related to linguistics. As stated by Marcinkowski (2009: 68) "research articles have become increasingly important 
for the communication of findings in the sciences and establishing membership of the scientific discourse community." The material under investigation is taken from an international scientific journal published by the Department of English and American Studies, Faculty of Arts, Constantine the Philosopher University in Nitra, Slovakia, titled Topics in Linguistics. The research corpus comprises ten research articles (five by native speakers of English, five by non-native speakers of English) of similar length taken from the above mentioned source. The texts for this study were selected randomly, the only criterion applied was the origin of the authors, because of the possible differences in the application of the presented structure by the native and non-native writers of English. The length of the research corpus was estimated to be 56,734 words $-28,349$ by nonnative speakers of English (Slovak writers only) and 28,285 by native speakers of English. The research articles were published between 2007 and 2012 and the data was gathered in June 2014. In all of the research articles the structure contains clearly identifiable sections such as the Introduction, Method, Results and Discussion or Possible Applications (Hill et al. 1982, as quoted in Swales 1990: 134). Three objectives have been stated in connection with to-infinitives in the selected corpus. Firstly, to compare the proportion of to-infinitive clauses in both corpora - native and non-native research articles based on the major categories of subordinate clauses as proposed by Quirk et al. (1985: 1047) nominal, relative and adverbial. Secondly, to compare the possible functions of complement clauses in both corpora and, finally, to compare the expression of stance in research articles in connection with complement to-infinitive clauses. It is generally known that native and non-native speakers and writers of any language differ in their linguistic coding and encoding - morphological, syntactic, stylistic and pragmatic approach to the language. An interesting investigation into non-finite clauses, namely participle clauses in academic discourse has been carried out by Granger (1997: 185-198). She has researched the differences in the academic writing of native English students and EFL students and compared the results in terms of frequency of occurrence, syntactic pattern and discourse function. Her research brings out a statistically significant underuse of these clauses (-ed and -ing participles) by non-native learners of English. The most striking research in this field has been realized by Biber and Reppen (1998: 145-158) who compared native and learner perspectives on the use of complement clauses. Based on their extensive corpus study, "to-clauses are even more noteworthy, being much more common in all four learner groups (French, Spanish, Chinese, Japanese) than they are in any of the native registers" (ibid.: 150). Evaluating different genres of native discourse, to-clauses were the most prevalent in academic discourse and in contrast to that-clauses in conversation, 
fiction and news. The above mentioned findings, comparing native and learner perspectives in the use of non-finite clauses, inspired my own investigation in the field of academic prose (Kozáčiková 2010 2014). As already mentioned, my objectives aim at comparing and contrasting two samples - native and non-native writers of English. I assume almost identical language performance of these two samples, both being professionals with expert background in the research area, so they are relatively equal in their status. Thus, it is one of my primary objectives in this paper to analyse whether there are particular differences in the application of to-clauses by native and non-native writers of academic research articles and possibly to comment on the major similarities and differences.

\section{Nominal, relative and adverbial clauses}

Based on Quirk et al.'s (1985) subdivision to-clauses can be viewed as formal means of text formation and have nominal, relative and adverbial meaning. This functional classification resembles to some extent that of subclausal units such as noun phrases and adverbs. As complement (or nominal) clauses they may function as subject (including extraposed subject), direct object, subject complement, appositive and adjective complement (ibid.: 1061). Biber et al. (2002: 259) add the function of object predicative (Some of these issues dropped out of Mar's later works because he considered them to have been satisfactorily dealt with). As far as terminology is concerned, there has been a sort of discrepancy. While Quirk et al. (1985) think of postmodification by infinitive clauses and so its classification as a relative clause, Biber et al. (2002) take them as noun complement (They say that failure to take precautions against injuring others is negligent.), noun postmodifier (It is a callous thing to do.) or part of an adjective phrase (I think the old man's a bit afraid to go into hospital.). In their adverbial function toclauses refer mainly to adjunct purpose infinitive clauses (To open the carton, pull this tab.) and style disjunct comment clauses (I am not sure what to do, to be honest.). As for my own research, there has been a visible disbalance in the use of to-infinitive clauses by native and non-native writers of English in the selected corpus. As the results show, the number of subordinate to-infinitive clauses in the native writer corpus (266 clauses) is higher than in the non-native writer corpus (97 clauses). The reasons for this can originate in the structural syntactic differences between these two languages. A contrastive quantitative perspective on the types of the dependent clauses shows a certain similarity with the nominal clause as the most common and adverbial to-infinitive clause as the least common in both corpora. As can be observed in Table 1 below, the number of nominal clauses is higher than the number of the other dependent clauses in both corpora. 


\begin{tabular}{|l|l|l|}
\hline & NW & NNW \\
\hline NOMINAL & $156(58.49 \%)$ & $65(67.01 \%)$ \\
\hline RELATIVE & $69(26.03 \%)$ & $19(19.58 \%)$ \\
\hline ADVERBIAL & $41(15.47 \%)$ & $13(13.40 \%)$ \\
\hline
\end{tabular}

Table 1: Types of $t o$-infinitive clauses in the NW and NNW corpus

Even though my expectation was that non-finite to-infinitive clauses mainly in their nominal function can be predominantly found in the introductory parts of the research articles, where the aims, methods and objectives are stated, the results have not proved that. As the following examples illustrate, nominal clauses in both corpora refer mainly to post predicative functions having suggested an intentional meaning and occurring in all parts of the research articles.

(1) This would seem to be clarified by the second precept. (native writers - method)

(2) Its aims, it follows, is to identify the political and social inequalities existing in society. (non-native writers - results)

Taking into account the second major type of to-infinitive clause - defining relative clause in the analysed sample, its antecedent is typically abstract and merely understood.

...use of historical-comparative methods to trace their origin and development. (non-native writers)

(4) Despite the problematic nature of attempts to define the term, there are some points of general agreement. (native writers)

(5) Much of the research into discourse analysis tends to focus on the researcher's ability to identify patterns... (native writers)

In addition, adverbial to-infinitive clauses express mainly purpose meanings, as the first clause of the sentence, and quite unexpectedly, no to-infinitive comment clause has been found in the above mentioned sample.

(6) It is named international English in order to distinguish it from the American variety. (non-native writers) 
Biber (2006: 84) claims that to-complement clauses are the most common in the directive registers, thus the main functions of these clauses are quite predictable. Even though Biber did not fully analyse the main functions of complement clauses in academic discourse, he proposed a detailed analysis of the semantic categories of verbs - verbs of cognition, perception, intention etc. in post predicative to-clauses (Biber et al. 2002: 332-333). Coming back to my own research, I expect the functions of subject complement and object as the most prevailing. As demonstrated in the table below, my expectations were proved with the subject complement as the most common in native writer sample and equally direct object and subject complement in non-native writer discourse. At this stage, no statistically significant differences have been investigated in the analysed corpora (cf. Table 2). In their subject complement function, the most common verbs that control to-clause in the selected corpora are copula verbs seem, appear and be suggesting planned intended meaning in some cases with future reference (9).

(7) The conception of cognitive stylistics, which suggests viewing context as a cognitive entity, seems to be addressing the main concerns of translation. (nonnative writers)

(8) This is not to criticize the kind of textual analysis that has been carried out so extensively in corpus linguistics over recent year. (native writers)

(9) The aim of this study will be.... (non-native writers)

\begin{tabular}{|l|l|l|}
\hline & NW & NNW \\
\hline SUBJECT & $11(7.09 \%)$ & $12(18.46 \%)$ \\
\hline OBJECT & $77(49.35 \%)$ & $24(36.92 \%)$ \\
\hline SUBJECT COMPLEMENT & $55(35.26 \%)$ & $24(36.92 \%)$ \\
\hline APPOSITION & $2(1.28 \%)$ & $2(3.07 \%)$ \\
\hline COMPLEMENT OF O & $8(5.12 \%)$ & $1(1.53 \%)$ \\
\hline COMPLEMENT OF Adj & $3(1.92 \%)$ & $2(3.07 \%)$ \\
\hline
\end{tabular}

Table 2: Functions of to-infinitive clauses in the NW and NNW corpus

As the research results indicate, there has been observed a considerable amount of the extraposed subject clauses with evaluative adjectives (difficult, 
crucial, important, relevant etc.) primarily in non-native writers discourse, as in the following examples:

(10) It is not difficult to define openly slanted or biased expressions of political nature. (non-native writers)

(11) It is crucial for translator to pay close attention to these aspects of the source text... (non-native writers)

This more or less shows that even though academic writing is praised for highly formal and impersonal language, the use of appropriate terminology, clear arguments and straightforward text organization (Kozáčiková 2010: 28), it is quite common to use extraposed subject to-infinitive clauses in order to show the author's stance and personal attitudes to the discussed subject matter.

\section{The expression of stance and to-infinitive clause}

The role of stance in academic writing has already been outlined by different authors who refer to stance as evaluation (Hunston 1994) or evidentiality (Chafe et al. 1986) or hedges (Hyland 1998). By allowing writers to express their uncertainty concerning the factuality of their statements or to indicate deference to their readers, stance and its formal and semantic realization is becoming a significant characteristic of academic prose. According to Biber (2006: 87) stance expressions convey many different kinds of personal feelings and assessments, including attitudes that a speaker has about information, how certain they are about its veracity, how they obtained access to the information, and what perspective they are taking. The analysis presented here focuses on the grammatical expression of stance in connection with to-infinitive complement clauses inspired by Biber's classification (2006: 92-93) on stance clauses controlled by verbs, adjectives and nouns. In my research, I have tried to investigate the main aspects of nominal to-clauses as stance markers in two patterns - stance verb + to-infinitive clause and stance adjective + to-infinitive clause in both corpora - native and non-native scientific research article writing. The extensive research carried out by Biber comprises the expression of stance in university registers, specifically in spoken academic register (classroom teaching, class management, labs, office hours, study groups, service encounters) and written university register as textbooks, course packs, syllabi and institutional writing. Surprisingly, the concept of scientific research writing is not included in his research and there is an attempt to fill this gap in the presented research. Table 3 below presents the occurrence of stance in connection with to-infinitive clauses in the native and non-native linguistics research papers. 


\begin{tabular}{|l|l|l|}
\hline & NW & NNW \\
\hline The number of nominal $t o$-clauses & 156 & 65 \\
\hline Stance & $98(62.82 \%)$ & $37(57 \%)$ \\
\hline a. Stance verb + to-clause & 82 & 21 \\
\hline b. Stance adjective + to-clause & 16 & 16 \\
\hline No stance & $58(37.17 \%)$ & $28(43 \%)$ \\
\hline
\end{tabular}

Table 3: Nominal to-clauses in NW and NNW corpus

As the results show, there is an observable tendency for stance in connection with to-infinitive clauses in native writer discourse. Even though stance prevails in non-native discourse, the number of these clauses is not so significant as in native writer sample. Nominal to-infinitive clauses in both corpora are connected mainly with stance verbs such as verbs of desire, verbs of causation-effort, mental verbs, probability verbs and communication verbs. Let me illustrate them with examples taken from my research material:

(12) Students are expected to reflect on the course... - stance verb-mental verb plus to-infinitive (native writers)

(13) This would seem to be clarified by the second precept. - nominal, Cs stance verb probability plus to-infinitive (non-native writers)

(14) Norman Fairclough, in his work Language and Power (1989) wishes to examine how the ways in which we communicate are constrained ... - stance verb (verb of desire) plus to-infinitive (non-native writers)

(15) They also help to accomodate target text factors - nominal, O stance verb - verb of causation-effort plus to clause (non-native writers)

Referring back to Biber's classification of stance verbs + to-clauses, he claims that verbs of desire are the most common class controlling to-clauses, especially in spoken academic register. Based on his findings (2006: 108), verbs of causation-effort are relatively common in written and spoken registers, mental verbs (e.g. is assumed, is believed) and probability verbs (e.g. seem, tend) are less frequent overall in both registers. On the contrary, in the corpus presented here - NW and NNW scientific research papers - verbs of causation-effort (e.g. help, try, seek, intend) were found as the most common class connected with 
writers' attempts to present their research outcomes or possible implications of their research.

(16) Here are some comments on Anton Chekhov's story The Lady with the Little Dog based on an approach which I aim to develop in future work (XY, in preparation). (native writers)

(17) This post-task data analysis activity was intended to heighten their awareness of the aforementioned forms and to give students an overview of specific academic discourse found throughout their course book. (native writers)

(18) Understanding particular inferences can help us to understand how ... (native writers)

As presented in Table 4 bellow, the category of mental verbs is the most common (together with verbs of causation-effort) in non-native writer discourse. These verbs typically refer to mental states or events and it is interesting to see that in the analysed corpus they are used to protect writers from possible criticism and disagreement $(19,20,21)$. In native writer corpus the same aim is achieved through probability verbs and refers to lessening the risk of a face-threatening act $(22,23)$.

(19) It is assumed to be rather difficult to agree on ... etc. (non-native writers)

(20) Some metaphorical patterns are considered to be universal ... etc. (non-native writers)

(21) All languages in EU are believed to be equal ... etc. (non-native writers)

(22) Two metaphors seem to dominate the text ... etc. (native writers)

(23) Its concept seems to be addressing the main concerns of translation. (non-native writers)

\begin{tabular}{|l|l|l|}
\hline VERBS & NW (21) & NNW (82) \\
\hline Verb of desire + to-clause & 5 & 18 \\
\hline Verb of causation-effort + to-clause & 6 & 26 \\
\hline Mental verb + to-clause & 6 & 12 \\
\hline Probability verb + to-clause & 4 & 21 \\
\hline Communication verb + to-clause & 0 & 5 \\
\hline
\end{tabular}

Table 4: Stance verb plus to-clause 
An academic research article, as a specific genre of academic prose, heavily relies on fact and objective explanations; however, a professional evaluation and assessment - whether positive or negative is needed. For these purposes, mainly evaluation adjectives with extraposition occur in the selected corpus. These constructions typically comment on the status of the information provided in the research article, as illustrated here:

It is important to expose hidden things, since they are not evident for the individuals involved. (non-native writers)

(25) But it is very misleading to claim that its description of text uniquely captures the reality of language as experienced by its users. (non-native writers)

\section{Conclusion}

Let me now proceed to tentative conclusions that can be drawn from the research presented above. The present analysis has, of course, its limitations, which mainly include the limited number of texts in the corpora and the native language of non-native speakers, which was Slovak. The question whether the results of the study will vary according to the native language of non-native speakers will be one of the crucial questions in my further research, since the language of non-native speakers may influence their choice of linguistic structures in English. Despite these limitations, the outcomes of my analysis seem to suggest that to-clauses are frequently used by both native and non-native writers of English, with quite frequent occurrence in native discourse (cf. Table 1 above). The analysis of the corpora mentioned above seems to reveal similarities and differences, some of which need to be futher investigated in my future research. A comparative analysis shows that in both corpora complement nominal to-infinitive clauses become the most dominant, mainly in the function of object and subject complement. This may be interpreted as the authors' attempts to communicate facts and develop arguments in a straightforward way (e.g. her idea is to allow, the message tends to distract, my strategy was to present). Considering stance, its importance in academic writing is increasing due to the fact that nowadays a researcher faces many different sources of the information. Therefore he/she needs to possess the ability to fully assess and evaluate the status of the data obtained. As noted in Section 4 of this paper, apart from some other expressions which refer to stance, for instance, modals and adverbs, toclauses as stance markers are relatively common in academic prose, specifically in the combination of stance verbs of causation and effort plus to-infinitive clauses. This more or less reflects the explanatory and surprisingly persuasive 
character of scientific research writing. The research results presented here lead us to the conclusion that even though several differences between two studied groups - non-native writers and native writers - are noticed, both samples are, when simplifying, more similar than different with the outstanding knowledge in the field and the use of similar grammatical patterns in English.

\section{References}

Alexander, L. G. (1988) Longman English Grammar. Essex: London.

Biber, D., Conrad, S. and Leech, G. (2002) Longman Student Grammar of Spoken and Written English. Harlow: Longman.

Biber, D. and Conrad, S. (2009) Register, Genre and Style. Cambridge: Cambridge University Press.

Biber, D. and Reppen, R. (1998) 'Comparing native and learner perspectives on English grammar.' In: Granger, S. (ed.) Learning English on Computer. London: Addison Wesley Longman. 145-158.

Biber, D. (2006) A Corpus-Based Study of Spoken and Written Registers. Amsterdam and Philadelphia: John Benjamins.

Biber, D. and Gray, B. (2010) 'Challenging stereotypes about academic writing: Complexity, elaboration, explicitness.' Journal of English for Academic Purposes 9 (1), 2-20.

Chafe, W. L. and Nichols, J. (eds) (1986) Evidentiality: The Linguistic Coding of Epistemology. Norwood, NJ: Ablex.

Granger, S. (1997) 'On identifying the syntactic and discourse features of participle clauses in academic English: Native and non native writers compared.' In: Aarts, J., de Mönnink, I. and Wekker H. (eds) Studies in English Language and Teaching. Amsterdam: Rodopi. 185-198.

Hill, S., Soppelsa, B. and West, G. (1982) 'Teaching ESL students to read and write experimental research papers.' TESOL Quarterly 16(3): 333-347

Huddleston, R. and Pullum, G. K. (2005) A Student's Introduction to English Grammar. Cambridge: Cambridge University Press.

Hunston, S. (1994) 'Evaluation and organization in a sample of written academic discourse.' In: Coulthard, M. (ed.) Advances in Written Text Analysis. London: Routledge. 191- 218.

Hyland, K. (1998) Hedging in Scientific Research Articles. Amsterdam and Philadelphia: John Benjamins.

Kozáčiková, Z. (2010) 'The use of non-finite clauses in written academic discourse. In: Jančař́ková, R. (ed.) Interpretation of Meaning across Discourses. Brno: Masaryk University. 25-33.

Leech, G., Svartvik, J. (1994) A Communicative Grammar of English. London: Longman.

Marcinkowski, M. (2009) 'Persuasive features in academic writing.' Topics in Linguistics 2009(4), 68-72.

Quirk, R., Greenbaum, S., Leech, G. and Svartvik, J. (1985) A Comprehensive Grammar of the English Language. London: Longman.

Burton-Roberts, N. (1997) Analysing Sentences: An Introduction to English Syntax. $2^{\text {nd }}$ ed. London: Longman.

Swales, J. (1990) Genre Analysis: English in Academic and Research Settings. Cambridge: Cambridge University Press. 


\section{Sources}

Ciprianová, E. (2009) 'Metaphor in translation.’ Topics in Linguistics 2009 (4), 12-16.

Clark, B. (2009) 'The place near the thing where we went that time: An inferential approach to pragmatic stylistics.' Topics in Linguistics 2009 (3), 4-12.

Dawson, D. (2010) 'Discourse analysis in new media: Agency with modern technology.' Topics in Linguistics 2012 (9), 18-24.

Hitchcock, A. (2011) 'Questions of power and culture.' Topics in Linguistics 2011 (8), 17-29.

Horváth, J. (2007) 'Pre 9/11 Inaugural Address of President George W. Bush: Critical discourse analysis.' Topics in Linguistics 2007 (1), 58-61.

Jesenská, P. (2007) 'EUROSPEAK and ELF - English as a current global lingua franca.' Topics in Linguistics 2007 (1), 62-67.

Klapicová, E. (2011) 'The language and communication of chatgroups.' Topics in Linguistics 2011 (7), 19-24.

Lencho, M. (2007) '(Im)politeness in an American and Slovak context: Constructing identities and calibrating to them in the course of simple conversations.' Topics in Linguistics 2007 (1), 8-12.

Miššíková, G.(2009) 'Interfaces in stylistics: Aspects of style in translation.' Topics in Linguistics 2009 (3), 32-36.

Widdowson, H. (2007) 'Text and real language.' Topics in Linguistics 2007 (1), 4-7.

Zuzana Kozáčiková is Assistant Professor at the Department of English and American Studies, Faculty of Arts, Constantine the Philospher University in Nitra, Slovakia. She received her Ph.D. from the above-mentioned institution in 2009. Her research interests include syntactic strategies of various text types, aspects of text condensation in written academic discourse and teaching syntax through communicative methods. She is the author of several journal articles published in Slovakia and abroad and has presented her research outcomes at international conference meetings and workshops.

Address: Mgr. Zuzana Kozáčiková, Ph.D., Department of English and American Studies, Faculty of Arts, University of Constantine the Philosopher, Štefánikova 67, 94901 Nitra, Slovakia. [e-mail:zkozacikova@ukf.sk] 